\title{
VALOR NUTRITIVO DE GRAMÍNEAS FORRAGEIRAS TROPICAIS IRRIGADAS EM DIFERENTES ÉPOCAS DO ANO ${ }^{1}$
}

\author{
Carlos Augusto Brasileiro de Alencar ${ }^{2}$, Rubens Alves de Oliveira ${ }^{3}$, Antônio Carlos Cóser ${ }^{4}$, Carlos Eugênio Martins ${ }^{4}$, \\ Fernando França da Cunha², José Luis Aguiar Figueiredo², Paulo Roberto Cecon ${ }^{3}$, Brauliro Gonçalves Leal ${ }^{3}$
}

\section{ABSTRACT \\ NUTRITIVE VALUE OF IRRIGATED \\ TROPICAL FORAGE GRASSES IN DIFFERENT SEASONS}

Bromatological composition and in vitro dry matter digestibility (IVDMD) of six forage grasses, under different irrigation depths and seasons, were evaluated. The experiment was carried out in a completely randomized arrangement, with two replications, in a split-split plot design. Six grass species (Xaraés, Mombaça, Tanzânia, Pioneiro, Marandu, and Estrela) constituted the plots, six irrigation depths $(0 \%, 18 \%, 45 \%, 77 \%$, $100 \%$, and $120 \%$ of the reference) the split-plots, and two seasons (autumn/winter and spring/summer) the split-split-plots. In order to vary irrigation depths, a line source sprinkler system was used. Raw protein (RP), neutral detergent fiber (NDF), and IVDMD were evaluated. Higher RP and IVDMD levels were found in autumn/winter and higher NDF in spring/summer. Irrigation depths affected Xaraés, Mombaça, and Estrela IVDMD, but did not affect their RP and NDF. Pioneiro presented higher RP and lower NDF, while Xaraés and Estrela presented higher and lower IVDMD, respectively.

KEY-WORDS: Line source sprinkler system; neutral detergent fiber; raw protein.

\section{INTRODUÇÃO}

O desempenho de animais, entre outros fatores, depende do consumo e da qualidade da matéria seca da pastagem consumida, pois determinam a quantidade de nutrientes ingeridos pelos animais, necessários às suas exigências de manutenção e produção (Gomide 1993). Já a eficiência de utilização de plantas forrageiras pelos animais depende de vários fatores, como a qualidade e quantidade de forragem disponível na pastagem e o potencial genético do animal. Assim, quando a disponibilidade de

\section{RESUMO}

Objetivou-se avaliar a composição bromatológica e a digestibilidade in vitro da matéria seca (DIVMS), em seis capins manejados por pastejo, sob efeito de diferentes lâminas de irrigação e estações do ano. O experimento foi conduzido em delineamento inteiramente casualizado, no esquema de parcelas subsubdivididas, com duas repetições, tendo nas parcelas seis gramíneas (Xaraés, Mombaça, Tanzânia, Pioneiro, Marandu e Estrela), nas subparcelas seis lâminas de irrigação $(0 \%, 18 \%$, $45 \%, 77 \%, 100 \%$ e $120 \%$ da referência) e nas subsubparcelas as estações outono/inverno e primavera/verão. Para diferenciar a aplicação das lâminas de irrigação, utilizou-se o sistema por aspersão em linha. Foram avaliados os teores de proteína bruta (PB), fibra em detergente neutro (FDN) e a DIVMS. Maiores teores de PB e DIVMS foram encontrados no outono/inverno e maiores teores de FDN na primavera/verão. As lâminas de irrigação influenciaram a DIVMS dos capins Xaraés, Mombaça e Estrela e não alteraram os teores de PB e FDN. O capim Pioneiro apresentou maiores e menores teores de PB e FDN, respectivamente. Os capins Xaraés e Estrela apresentaram maiores e menores DIVMS, respectivamente.

PALAVRAS-CHAVE: Aspersão em linha; fibra em detergente neutro; proteína bruta.

forragem e o potencial do animal não são limitantes, a qualidade do pasto é definida pela produção por animal, sendo diretamente relacionada ao consumo voluntário e à disponibilidade de nutrientes (Reis \& Rodrigues 1993).

$\mathrm{O}$ valor nutritivo da forragem varia, ao longo do ano, em áreas irrigadas, em comparação às pastagens não irrigadas. Durante períodos de veranico e, principalmente, no inverno, ocorre queda no valor nutritivo dos pastos. A suplementação de água, por meio de irrigação, pode alterar a composição bromatológica e a qualidade das plantas. O valor nutritivo

1. Trabalho recebido em maio/2008 e aceito para publicação em mar./2010 (n registro: PAT 3994/ DOI: 10.5216/pat.v40i1.3994).

2. Universidade Vale do Rio Doce, Faculdade de Ciências Agrárias, Departamento de Agronomia, Governador Valadares, MG,

Brasil.E-mails: c.brasileiro@yahoo.com.br, cunhaff@yahoo.com.br, joseluis@univale.br.

3. Universidade Federal de Viçosa, Centro de Ciências Agrárias, Departamento de Engenharia Agrícola, Viçosa, MG, Brasil.

E-mails: rubens@ufv.br, cecon@dpi.ufv.br, brauliro@ig.com.br.

4. Empresa Brasileira de Pesquisa Agropecuária, Centro Nacional de Pesquisa de Gado de Leite, Setor de Pastagem e Forragicultura, Juiz de Fora, MG, Brasil.E-mails: acoser@cnpgl.embrapa.br, caeuma@cnpgl.embrapa.br. 
refere-se à composição química da forragem e sua digestibilidade (Gerdes et al. 2000).

Vitor (2006), estudando o efeito da aplicação de diferentes lâminas de irrigação sobre o valor nutritivo do capim Elefante (Pennisetum purpureum Schum.), observou que o teor de proteína bruta e a digestibilidade in vitro da matéria seca (DIVMS) não foram influenciados pelas lâminas de irrigação. $\mathrm{O}$ teor de fibra em detergente neutro (FDN) foi influenciado positivamente pelas lâminas apenas no período chuvoso.

Vásquez (1965), estudando a interação entre níveis de nitrogênio e lâminas de irrigação nas forrageiras Panicum maximum Jacquin e Panicum purpurascens Raddi, observou que o nitrogênio aumentou o teor de proteína na forragem, sendo esse menor com o uso da irrigação. O significado prático para isso seria que, ao se usar irrigação, as forrageiras devem ser adubadas com nitrogênio, para que consigam manter seu teor protéico.

A eficiência de uso do adubo nitrogenado depende da umidade do solo. Plantas de Panicum maximum cv. Tobiatã, cultivadas em presença de estresse hídrico, apresentaram menor eficiência de uso do nitrogênio, bem como de fósforo e potássio (Dias Filho et al. 1991).

Marcelino et al. (2003), estudando o efeito da disponibilidade de água e da adubação nitrogenada, em áreas cultivadas com Tifton 85 (Cynodon dactylon), observaram que a maior eficiência de uso do nitrogênio foi obtida na condição de maior umidade do solo.

Objetivou-se, com este trabalho, avaliar o valor nutritivo estacional de seis gramíneas forrageiras, submetidas a diferentes lâminas de irrigação.

\section{MATERIAL E MÉTODOS}

O trabalho foi conduzido no período de maio de 2003 a abril de 2005, na área experimental da Universidade Vale do Rio Doce, em Governador Valadares, MG (18 47'30" de latitude Sul, 41 '59'04"'de longitude Oeste e altitude de $223 \mathrm{~m}$ ).

As médias de precipitação e evapotranspiração de referência $\left(\mathrm{ET}_{0}\right)$, durante os dois anos de experimento, foram de $1.064 \mathrm{~mm}$ e $1.277 \mathrm{~mm}$, respectivamente. Na Figura 1, estão representados os dados de
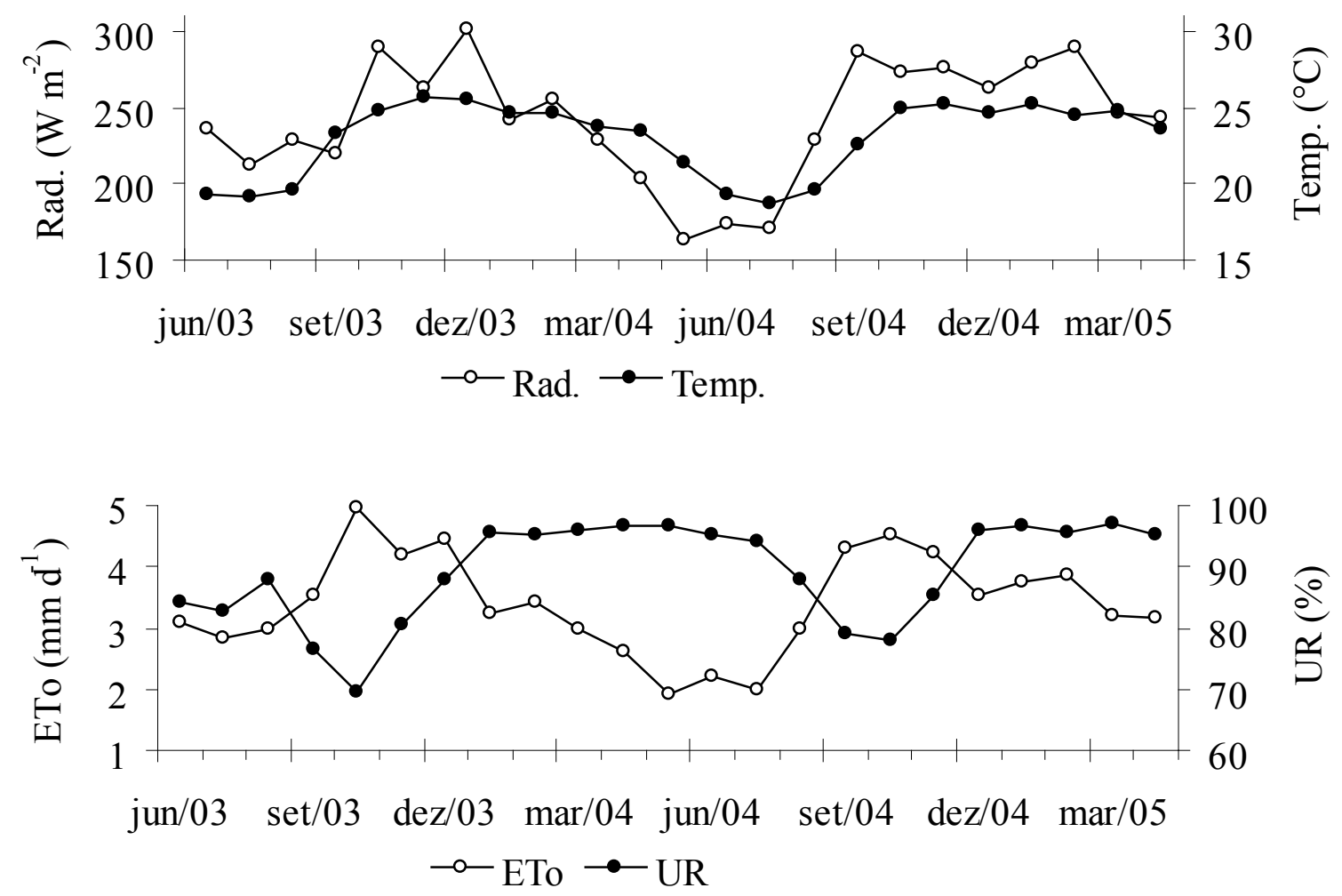

Figura 1. Variação mensal da radiação solar (Rad.), temperatura média do ar (Temp.), evapotranspiração de referência (ETo) e umidade relativa (UR), no período de maio de 2003 a abril de 2005 (Governador Valadares, MG). 
radiação solar, temperatura, evapotranspiração de referência $\left(\mathrm{ET}_{0}\right)$ e umidade relativa.

O solo, na área experimental, foi classificado como Cambissolo eutrófico, textura média. Fez-se análise química para este solo (Tabela 1) e corrigiuse a acidez, seguindo recomendações da CFSEMG (1999). A adubação de plantio consistiu de $100 \mathrm{~kg} \mathrm{ha}^{-1}$ de $\mathrm{P}_{2} \mathrm{O}_{5}$, na forma de superfosfato simples, aplicado no fundo do sulco. A adubação de manutenção anual consistiu de $50 \mathrm{~kg} \mathrm{ha}^{-1}$ ano $^{-1}$ de $\mathrm{P}_{2} \mathrm{O}_{5}, 150 \mathrm{~kg} \mathrm{ha}^{-1}$ ano $^{-1}$ de $\mathrm{K}_{2} \mathrm{O}$ e $300 \mathrm{~kg} \mathrm{ha}^{-1} \mathrm{ano}^{-1}$ de N, tendo como fontes o superfosfato simples, cloreto de potássio e ureia, respectivamente, sendo o fósforo aplicado em dose única, a cada ano, e o cloreto de potássio e a ureia parcelados em seis vezes, durante o ano.

A distribuição granulométrica e os resultados das análises físico-hídricas do solo foram os seguintes: argila $=30 \%$; silte $=25 \%$; areia $=45 \%$; capacidade de campo $=0,30 \mathrm{~g} \mathrm{~g}^{-1}$; ponto de murcha permanente $=0,17 \mathrm{~g} \mathrm{~g}^{-1}$ e densidade do solo $=$ $1,38 \mathrm{~g} \mathrm{~cm}^{-3}$. A densidade do solo foi determinada pelo método do anel volumétrico (Embrapa 1997) e os níveis de água no solo, na capacidade de campo e no ponto de murcha permanente, foram determinados para as tensões de $10 \mathrm{kPa}$ e $1.500 \mathrm{kPa}$, respectivamente. Os valores de retenção de água no solo foram determinados utilizando-se o método da Câmara de Richards (Richards 1949).

Adotou-se o delineamento inteiramente casualizado, no esquema de parcelas subsubdivididas, com duas repetições, tendo nas parcelas as gramíneas $B$. brizantha cv. Xaraés, P. maximum cv. Mombaça, $P$. maximum cv. Tanzânia, $P$. purpureum cv. Pioneiro, $B$. brizantha cv. Marandu e C. nlemfuensis L. cv. Estrela; nas subparcelas as lâminas de irrigação $\left(0 \mathrm{~mm}\right.$ ano ${ }^{-1}, 101 \mathrm{~mm}$ ano ${ }^{-1}, 252 \mathrm{~mm}$ ano ${ }^{-1}$, $431 \mathrm{~mm} \mathrm{ano}^{-1}, 560 \mathrm{~mm}^{2} \mathrm{ano}^{-1}$ e $672 \mathrm{~mm}^{2} \mathrm{ano}^{-1}$, correspondendo a $0 \%, 18 \%, 45 \%, 77 \%, 100 \%$ e $120 \%$ da referência, respectivamente); e nas subsubparcelas as estações do ano. O outono/inverno compreendeu os meses de abril a setembro e a primavera/verão os meses de outubro a março.
As parcelas experimentais tinham $6,0 \mathrm{~m}$ de largura e 18,0 m de comprimento. As parcelas foram subdivididas em seis partes iguais, resultando em subparcelas de $6,0 \mathrm{~m}$ x 3,0 m (18,0 m²). As lâminas de água foram obtidas pela distribuição de água na direção perpendicular à tubulação com os aspersores, por meio de aspersores em linha (Line Source Sprinkler System), conforme Hanks et al. (1976). A lâmina de irrigação adotada como referência (100\%) foi determinada por meio de monitoramento do potencial de água no solo, medido em tensiômetros instalados a $15 \mathrm{~cm}$ e $45 \mathrm{~cm}$ de profundidade. As irrigações foram efetuadas quando os tensiômetros instalados a $15 \mathrm{~cm}$ registraram valores de potencial matricial em torno de - $60 \mathrm{kPa}$. A lâmina de irrigação aplicada foi medida com pluviômetros instalados em cada subparcela experimental e calculada por meio da equação

$$
\mathrm{L}=\frac{(\mathrm{CC}-\theta)}{10} \mathrm{DZ} \frac{1}{\mathrm{Ea}}
$$

onde, $\mathrm{L}=$ lâmina total necessária $(\mathrm{mm}) ; \mathrm{CC}=$ capacidade de campo (em peso); $\theta=$ teor de água do solo, no potencial matricial de $-60 \mathrm{kPa}$ (em peso); $\mathrm{D}=$ densidade do solo $\left(\mathrm{g} \mathrm{cm}^{-3}\right) ; \mathrm{Z}=$ profundidade efetiva do sistema radicular $(\mathrm{cm})$; e Ea = eficiência potencial de aplicação de água (decimal).

Simultaneamente ao monitoramento da umidade do solo, via tensiometria, foram coletados dados meteorológicos diários, a partir de uma estação meteorológica automática, instalada dentro da área experimental.

O experimento foi conduzido sob manejo de pastejo, no qual foram utilizadas vacas mestiças (Holandês x Zebu) de $500 \mathrm{~kg}$ de média. Os animais foram utilizados apenas como agentes de corte, após as avaliações. Aos 45 dias após o corte de uniformização com roçadeira, foi realizado o primeiro pastejo, deixando-se um resíduo em torno de $15 \%$ de folhas verdes (Aroeira et al. 1999). O mesmo procedimento foi adotado até o final do experimento, porém com intervalos de trinta dias.

Tabela 1. Características químicas do solo, em amostras da área experimental, nas camadas de 0-0,30 m e 0,30-0,60 m (Governador Valadares, MG, 2003).

\begin{tabular}{|c|c|c|c|c|c|c|c|c|c|}
\hline Camada & \multirow{2}{*}{$\begin{array}{c}\mathrm{pH} \\
\mathrm{H}_{2} \mathrm{O}\end{array}$} & \multirow{2}{*}{$\frac{\text { M.O. }}{\mathrm{g} \mathrm{dm}^{-3}}$} & $\mathrm{P}$ & $\mathrm{K}^{+}$ & $\mathrm{Ca}^{+2}$ & $\mathrm{Mg}^{+2}$ & $\mathrm{Al}^{+3}$ & $\mathrm{H}+\mathrm{Al}$ & \multirow{2}{*}{$\begin{array}{l}\mathrm{V} \\
\%\end{array}$} \\
\hline $\mathrm{cm}$ & & & \multicolumn{2}{|c|}{$\mathrm{mg} \mathrm{dm}^{-3}$} & \multicolumn{4}{|c|}{$\mathrm{cmol}_{\mathrm{c}} \mathrm{dm}^{-3}$} & \\
\hline $0-30$ & 6,5 & 1,6 & 6,0 & 60,0 & 3,8 & 1,0 & 0,1 & 4,0 & 55,0 \\
\hline $30-60$ & 6,3 & 0,3 & 5,2 & 17,0 & 2,4 & 0,8 & 0,1 & 4,3 & 43,0 \\
\hline
\end{tabular}


Antes da entrada dos animais, as gramíneas foram avaliadas mediante a colocação de uma moldura retangular metálica de $1,0 \mathrm{~m}$ x 0,5 $\mathrm{m}\left(0,5 \mathrm{~m}^{2}\right)$. A unidade amostral foi posicionada em locais prédeterminados, evitando-se coletar amostras sucessivas nas mesmas áreas. A forragem foi colhida por meio da técnica de simulação de pastejo. Esta técnica consiste em colher, manualmente, forragem com características semelhantes à que seria apreendida pelos animais de cada piquete, geralmente lâmina foliar e parte do pseudocolmo. Toda a massa verde colhida foi acondicionada em sacos plásticos, devidamente identificados, e imediatamente pesada. Em seguida, foi retirada uma subamostra, novamente pesada, acondicionada em saco de papel identificado e colocada para secar em estufa com circulação de ar, a $60^{\circ} \mathrm{C}$, por 72 horas. Após secagem, as subamostras foram pesadas novamente, para obtenção da produtividade de matéria seca.

As amostras colhidas em cada estação foram reunidas e moídas em moinho do tipo Willey, em peneira de malha de um milímetro. Posteriormente, foram analisadas quanto aos teores de proteína bruta (PB) e fibra em detergente neutro (FDN), segundo Silva \& Queiroz (2002), e quanto à digestibilidade in vitro da matéria seca (DIVMS), segundo Tilley \& Terry (1963). Essas determinações foram realizadas no Centro Nacional de Pesquisa de Gado de Leite, da Empresa Brasileira de Pesquisa Agropecuária.

Os dados foram submetidos a análises de variância e regressão. A comparação de médias foi realizada usando-se o teste Tukey, a 5\% de signifi- cância. Para o fator quantitativo, os modelos foram escolhidos com base na significância dos coeficientes de regressão, utilizando-se o teste $\mathrm{t}$, a $10 \%$ de significância; no coeficiente de determinação $\left(\mathrm{R}^{2}\right)$; e no fenômeno biológico. Para execução das análises estatísticas, foi utilizado o software SAEG 9.0.

\section{RESULTADOS E DISCUSSÃO}

Verificou-se interação $(\mathrm{p}<0,05)$ entre os fatores estação do ano e capim, para todos os parâmetros estudados. Na estação primavera/verão, os capins Pioneiro e Tanzânia apresentaram maior e menor teores de proteína bruta (PB), respectivamente (Tabela 2). Santos et al. (2003), avaliando diversas forrageiras irrigadas no município de Recife (PE), também verificaram que Pioneiro foi o capim que apresentou maior teor de PB. Na estação outono/inverno, os capins Pioneiro e Estrela apresentaram maiores teores de proteína bruta $(\mathrm{PB})$ e não diferiram $(\mathrm{p}>0,05)$ dos capins Tanzânia e Mombaça (Tabela 2). Por outro lado, os capins do gênero Brachiaria apresentaram os menores teores de PB. Essas diferenças de teores de $\mathrm{PB}$, entre os capins estudados, podem ser explicadas com base na produtividade de matéria seca.

Os teores de PB encontrados no presente trabalho são superiores a outros existentes na literatura. Santos et al. (2003) apresentou teores de PB de 10,2; 7,3; 7,2; e 7,0, para os capins Pioneiro, Tanzânia, Marandu e Mombaça, respectivamente. Os valores apresentados por esses autores foram menores que os encontrados no presente trabalho, em razão, pos-

Tabela 2. Valores médios de produtividade de matéria seca, proteína bruta, fibra em detergente neutro e digestibilidade in vitro da matéria seca, de capins cultivados sob pastejo, em diferentes estações do ano (Governador Valadares, MG, maio de 2003 a abril de 2005).

\begin{tabular}{|c|c|c|c|c|c|c|}
\hline Estação & Xaraés & Mombaça & Tanzânia & Pioneiro & Marandu & Estrela \\
\hline & \multicolumn{6}{|c|}{ Produtividade de matéria seca $\left(\mathrm{kg} \mathrm{ha}^{-1}\right.$ estação-1) } \\
\hline Outono/inverno & $5.972 \pm 779$ & $4.867 \pm 860$ & $4.678 \pm 722$ & $5.107 \pm 513$ & $4.670 \pm 445$ & $5.363 \pm 885$ \\
\hline \multirow[t]{2}{*}{ Primavera/verão } & $7.968 \pm 409$ & $6.476 \pm 517$ & $6.222 \pm 474$ & $6.641 \pm 624$ & $6.247 \pm 603$ & $6.961 \pm 821$ \\
\hline & \multicolumn{6}{|c|}{ Proteína bruta (\%) } \\
\hline Outono/inverno & $11,19 \mathrm{Ba}$ & $13,41 \mathrm{ABa}$ & $13,71 \mathrm{ABa}$ & $15,71 \mathrm{Aa}$ & $11,05 \quad \mathrm{Ba}$ & $15,33 \mathrm{~A}$ a \\
\hline \multirow[t]{2}{*}{ Primavera/verão } & $8,36 \mathrm{AB} \mathrm{b}$ & $8,60 \mathrm{AB} \quad \mathrm{b}$ & $7,94 \quad \mathrm{~B} \quad \mathrm{~b}$ & $11,98 \mathrm{~A} \mathrm{~b}$ & $10,25 \mathrm{ABa}$ & $11,25 \mathrm{AB} \quad \mathrm{b}$ \\
\hline & \multicolumn{6}{|c|}{ Fibra em detergente neutro (\%) } \\
\hline Outono/inverno & $67,56 \mathrm{ABa}$ & $70,15 \mathrm{Aa}$ & $68,98 \mathrm{AB} \quad \mathrm{b}$ & $62,32 \mathrm{~B} \mathrm{~b}$ & $66,88 \mathrm{ABa}$ & $72,85 \mathrm{Aa}$ \\
\hline \multirow[t]{2}{*}{ Primavera/verão } & $69,39 \mathrm{~A}$ a & $71,01 \mathrm{Aa}$ & $72,77 \mathrm{~A} \quad \mathrm{a}$ & $69,42 \mathrm{~A}$ a & $68,12 \mathrm{~A} \quad \mathrm{a}$ & $74,96 \mathrm{Aa}$ \\
\hline & \multicolumn{6}{|c|}{ Digestibilidade in vitro da matéria seca (\%) } \\
\hline Outono/inverno & $60,81 \mathrm{Aa}$ & $60,49 \mathrm{~A} a$ & $61,43 \mathrm{~A} \mathrm{a}$ & $52,03 \mathrm{ABa}$ & $52,36 \mathrm{ABa}$ & $44,55 \mathrm{Ba}$ \\
\hline Primavera/verão & $48,79 \mathrm{~A} \mathrm{~b}$ & $43,31 \mathrm{AB} \quad \mathrm{b}$ & $47,68 \mathrm{AB} \quad \mathrm{b}$ & $50,07 \mathrm{~A} \quad \mathrm{a}$ & $50,23 \mathrm{~A} \quad \mathrm{a}$ & $38,48 \mathrm{~B} \quad \mathrm{~b}$ \\
\hline
\end{tabular}


sivelmente, de o manejo adotado ter sido por corte, o intervalo de corte ser maior (35 dias) e a adubação nitrogenada menor (50 kg ha-1 $\left.\mathrm{ano}^{-1}\right)$. França et al. (2007) observaram que o teor de PB aumentou, à medida que cortes foram realizados com maior frequência e maiores doses nitrogenadas foram aplicadas. Cecato et al. (2001), avaliando o capim Estrela, no município de Maringá (PR), encontraram teores de $\mathrm{PB}$ variando de $10,1 \%$ a $18,7 \%$. No caso do capim Xaraés, Euclides (2002) encontrou teor de PB de $10,3 \%$.

Com exceção do capim Marandu, verificouse, também, na Tabela 2, que os teores de PB foram maiores $(\mathrm{p}<0,05)$ na estação outono/inverno. $\mathrm{Na}$ literatura, encontra-se comportamento diferente, em que a estação primavera/verão proporciona maiores teores de PB. Machado et al. (1998), avaliando os capins Mombaça e Tanzânia, também verificaram maiores teores de PB na estação chuvosa (primavera/ verão), em relação à estação seca (outono/inverno). Gerdes et al. (2000), avaliando os capins Marandu e Tanzânia, no município de Nova Odessa (SP), em cultivo de sequeiro, com intervalos de corte de 35 dias e adubação nitrogenada de $100 \mathrm{~kg} \mathrm{ha}^{-1} \mathrm{ano}^{-1}$, observaram que os teores de PB foram de $17 \%$ e $12 \%$, nas estações primavera/verão e outono/inverno, respectivamente. Os teores de proteína bruta mais elevados, na estação outono/inverno, observados neste trabalho, podem ser atribuídos a um provável efeito de concentração de $\mathrm{N}$ na forragem, por causa dos menores rendimentos de matéria seca obtidos.

As diferentes lâminas de irrigação não proporcionaram alterações nos teores de $\mathrm{PB}$ dos capins estudados. Vitor (2006), no município de Viçosa (MG), também não verificou efeito das lâminas de irrigação no teor de PB do capim Elefante. Cunha et al. (2007) encontraram resultados diferentes, avaliando o capim Tanzânia, no município de Viçosa (MG). Estes autores encontraram menores teores de PB, nos tratamentos que receberam maiores lâminas de irrigação. $O$ fato de a lâmina de irrigação não ter afetado o teor de PB pode ser explicado com base na metodologia para obtenção das amostras. Foi colhido o material potencialmente consumível, ou seja, apenas folha. Se tivesse sido avaliado juntamente com essas folhas, o colmo, talvez, houvesse influenciado.

$\mathrm{Na}$ Tabela 2, verifica-se que os capins, na estação primavera/verão, não apresentaram diferença $(p>0,05)$ no teor de fibra em detergente neutro (FDN). Na estação outono/inverno, observou-se que o capim Pioneiro apresentou menor teor de FDN $(p<0,05)$ e que os capins Estrela e Mombaça apresentaram os maiores $(\mathrm{p}<0,05)$ teores de FDN. Segundo Balsalobre (2002), as plantas do gênero Cynodon, gênero do capim Estrela, são caracterizadas por possuírem alta proporção de FDN, apresentando, no entanto, teor de lignina relativamente baixo, o que lhes confere boa qualidade.

Os teores de FDN encontrados para os capins Mombaça e Tanzânia ficaram abaixo de 75\% (Tabela 2). Euclides (1995), estudando diversas cultivares do gênero Panicum, concluiu que valores de FDN inferiores a 55\% são raros e valores superiores a $65 \%$ comuns em tecidos novos, enquanto teores entre $75 \%$ e $80 \%$ são encontrados em forragem de maturidade avançada. Considerando-se que a metodologia utilizada (intervalo entre desfolha de 30 dias) confere ao material colhido tecidos novos, esses valores corroboram os valores citados por Euclides (1995). Santos et al. (2003), trabalhando com diversas forrageiras irrigadas, no município de Recife (PE), encontraram os seguintes teores de FDN: Pioneiro: 68,1\%; Marandu: 74,8\%; Mombaça: 77,5\%; e Tanzânia: 79,2\%. Para o capim Xaraés, Euclides (2002) citou valor de $73,4 \%$.

A estação primavera/verão proporcionou maiores teores de FDN nos capins Tanzânia e Pioneiro. Nos demais tratamentos, não foi verificado efeito das estações do ano (Tabela 2). Esse resultado não era esperado, pois, com o rápido alongamento da folha dos capins, na estação primavera/verão, a participação do constituinte parede celular deveria ser maior e, consequentemente, o teor de FDN também. Machado et al. (1998) verificaram, também, o mesmo comportamento, em que os teores de FDN, no período chuvoso, foram de $73,4 \%$ e $75,1 \%$, enquanto, no período seco, foram de $69,6 \%$ e $70,1 \%$, para os capins Mombaça e Tanzânia, respectivamente. Gerdes et al. (2000) verificaram, em geral, que as estações primavera e verão proporcionaram teores de FDN em torno de $17,7 \%$ e $15,9 \%$, maiores que os das estações outono e inverno, nos capins Marandu e Tanzânia, respectivamente. Em razão, possivelmente, de o material colhido ter sido apenas folha, os capins Xaraés, Mombaça, Marandu e Estrela, quando comparados, nessas condições experimentais, apresentam pequena variação na qualidade da forragem.

Como verificado para proteína bruta, as diferentes lâminas de irrigação também não proporcionaram alterações nos teores de FDN dos capins 
avaliados (Tabela 2). Cunha et al. (2007) e Sória (2002), trabalhando com capim Tanzânia, e Barreto et al. (2001), com capim Elefante, também não encontraram respostas do teor de FDN ao aumento da lâmina de irrigação. Apesar da não resposta, alguns autores relatam que plantas submetidas a estresse hídrico apresentam menor teor de parede celular (Wilson 1983, Halim et al. 1989).

Independentemente da estação do ano, o capim Estrela foi o que apresentou menor digestibilidade in vitro da matéria seca (DIVMS) (Tabela 2). Esse resultado pode ser explicado pelo fato de esse capim possuir maior FDN. Os valores de DIVMS das cultivares de Panicum estão abaixo dos encontrados por Machado et al. (1998), que foram de 64,6\% e 63,4\%, no período chuvoso, e $64,8 \%$ e $66,9 \%$, no seco, para os capins Mombaça e Tanzânia, respectivamente. Quanto à DIVMS encontrada no capim Estrela, seus valores também estão abaixo dos obtidos por Cecato et al. (2001) $(61,2 \%)$ e Alvim et al. (2003) $(50,7 \%)$, que trabalharam com dose nitrogenada de $400 \mathrm{~kg} \mathrm{ha}^{-1}$ ano $^{-1}$, em Coronel Pacheco (MG). Sória (2002), utilizando maiores doses de adubo nitrogenado, observou maiores valores de DIVMS, concluindo que a aplicação desse adubo traz benefícios não apenas à quantidade produzida, mas, também, à qualidade, pois a digestibilidade é um dos melhores previsores da qualidade da forragem.

Ao estudar o efeito das estações do ano, verificou-se, nos capins Xaraés, Mombaça, Tanzânia e Estrela, que a estação outono/inverno proporcionou maior DIVMS, em relação à estação primavera/verão. Nos demais tratamentos, não houve influência da estação do ano nos valores de DIVMS (Tabela 2). Altas temperaturas promovem rápido crescimento $\mathrm{e}$ desenvolvimento da folha e aumento do teor dos componentes da parede celular e, como consequência, também a participação desse componente na matéria seca total da planta. Segundo Wilson (1983), esses efeitos estão negativamente correlacionados com a DIVMS. Gerdes et al. (2000) constataram, em geral, que as estações outono e inverno proporcionaram DIVMS em torno de $6,9 \%$ e $11,2 \%$ maiores que na primavera e no verão, nos capins Marandu e Tanzânia, respectivamente. Machado et al. (1998) também verificaram o mesmo para o capim Tanzânia.

Verificou-se interação significativa entre os fatores lâmina de irrigação e capins, para os teores de DIVMS. Observou-se que, com o aumento das lâminas de irrigação, os teores de DIVMS ajustaram-se, segundo uma regressão quadrática $(\mathrm{p}<0,05)$, para os capins Xaraés, Mombaça e Estrela (Figura 2), cujos valores máximos retirados das equações de regressão foram para as lâminas de irrigação de $90 \%, 66 \%$ e $40 \%$ da referência, respectivamente. Os demais capins não foram afetados. Há, na literatura, certa controvérsia quanto à influência da lâmina de irrigação sobre a digestibilidade da forragem. Cunha et al. (2007) e Sória (2002) não encontraram respostas da DIVMS do capim Tanzânia e Barreto et al. (2001) não encontraram respostas da DIVMS do capim Elefante. Todavia, Mislevy \& Everet (1981) e Dias Filho et al. (1991) verificaram que os tratamentos submetidos às maiores lâminas de irrigação apresentaram menores valores de DIVMS.
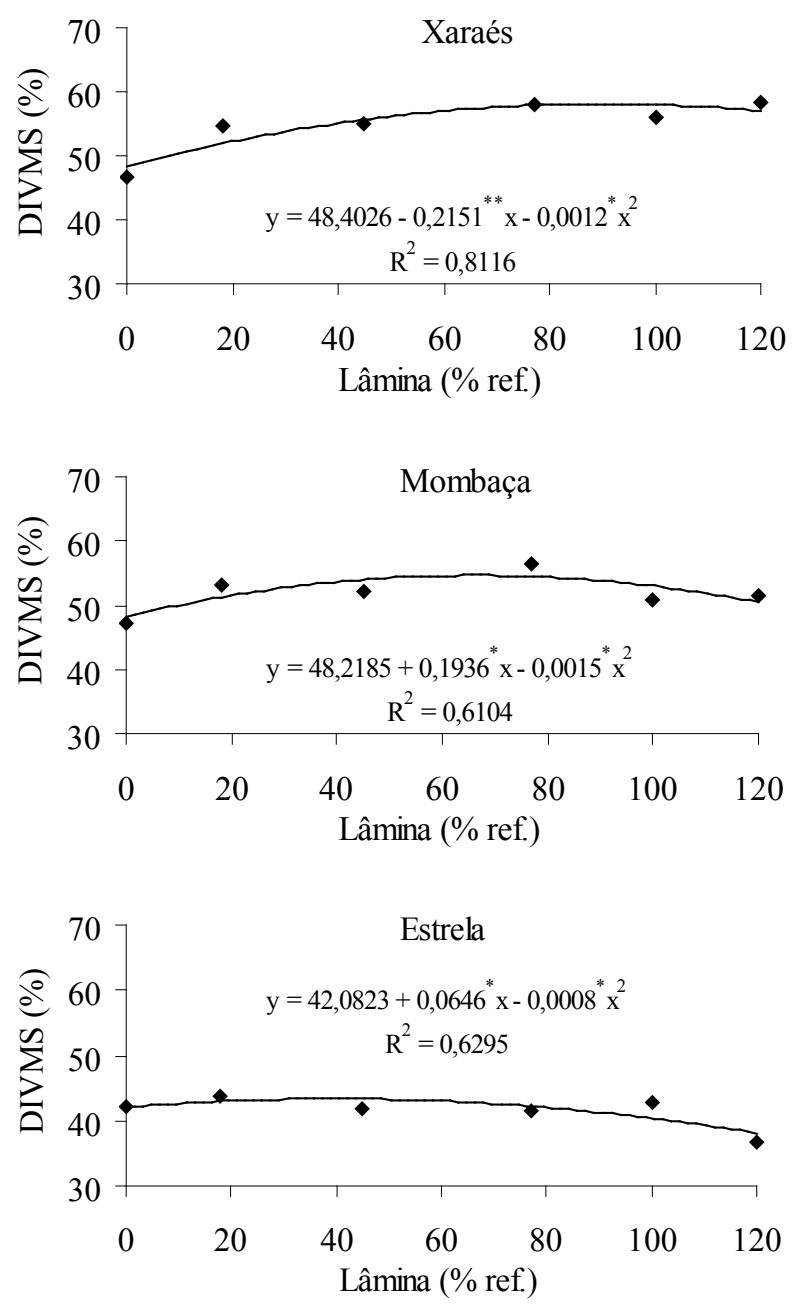

Figura 2. Digestibilidade in vitro da matéria seca (DIVMS), para os capins Xaraés, Mombaça e Estrela, em função das lâminas de irrigação (Governador Valadares, $\mathrm{MG}$, maio de 2003 a abril de 2005). $* *$ e $*$ significativo a $1 \%$ e $5 \%$ de probabilidade, respectivamente. 
Observou-se, no geral, com base nas avaliações bromatológicas ou DIVMS, que não houve diferenciação entre os capins do gênero Panicum. Da mesma forma, os capins Xaraés e Marandu, que são da espécie Brachiaria brizantha, também não diferiram. Segundo Euclides (1995), essas cultivares, comparadas sob as mesmas condições experimentais, apresentam pequena variação na qualidade da forragem.

\section{CONCLUSÕES}

1. O período outono/inverno proporciona maiores teores de proteína bruta e digestibilidade in vitro da matéria seca e menores teores de fibra em detergente neutro.

2. O aumento da lâmina de irrigação não afeta os teores de proteína e fibra. Os capins Xaraés, Mombaça e Estrela apresentam maior digestibilidade, quando irrigados com $90 \%, 66 \%$ e $40 \%$ da evapotranspiração, respectivamente.

3. Tanzânia, na estação primavera/verão, e as braquiárias, na estação outono/inverno, apresentam menores teores de proteína e Pioneiro os maiores. $\mathrm{Na}$ estação outono/inverno, Mombaça e Pioneiro apresentam maiores e menores teores de fibra, respectivamente. Xaraés e Estrela apresentam maiores e menores teores de digestibilidade, respectivamente.

\section{REFERÊNCIAS}

ALVIM, M. J. et al. Avaliação sob pastejo do potencial forrageiro de gramíneas do gênero Cynodon, sob dois níveis de nitrogênio e potássio. Revista Brasileira de Zootecnia, Viçosa, v. 32, n. 1, p. 47-54, 2003.

AROEIRA, L. J. M. et al. Pasture availability and dry matter intake of lactating crossbred cows grazing elephant grass (Pennisetum purpureum, Schum). Animal Feed Science and Technology, Amsterdam, v. 78, n. 3, p. 313324, 1999.

BALSALOBRE, M. A. A. Valor alimentar do capimtanzânia irrigado. 2002. 113 f. Tese (Doutorado em Zootecnia)-Escola Superior de Agricultura Luiz de Queiroz, Piracicaba, 2002.

BARRETO, G. P. et al. Avaliação de clones de capimelefante (Pennisetum purpureum Schum.) e de um híbrido com o milheto (Pennisetum glaucum (L.) R. Br.) submetidos a estresse hídrico: 2. Valor nutritivo. Revista Brasileira de Zootecnia, Viçosa, v. 30, n. 1, p. 7-11, 2001.
CECATO, U. et al. Teores de carboidratos não-estruturais, nitrogênio total e peso de raízes em Coastacross-1 (Cynodon dactylon (L.) Pers) pastejado por ovinos. Revista Brasileira de Zootecnia, Viçosa, v. 30, n. 3, p. 644-650, 2001.

COMISSÃO DE FERTILIDADE DO SOLO DO ESTADO DE MINAS GERAIS (CFSEMG). Recomendações para $o$ uso de corretivos e fertilizantes em Minas Gerais: $5^{\mathrm{a}}$ aproximação. 20. ed. Viçosa: Imprensa Universitária, 1999.

CUNHA, F. F. et al. Avaliação do sistema radicular do capim-tanzânia submetido a diferentes níveis de irrigação e turnos de rega. Engenharia na Agricultura, Viçosa, v. 15, n. 3, p. 200-211, 2007.

DIAS FILHO, M. B. et al. Digestibilidade in vitro da matéria orgânica e teor de proteína bruta em Panicum maximum Jacq. cv. Tobiatã sob estresse hídrico. Pesquisa Agropecuária Brasileira, Brasília, DF, v. 26, n. 10, p. 17251729, 1991

EMPRESA BRASILEIRA DE PESQUISA AGROPECUÁRIA (Embrapa). Manual de métodos de análise de solo. 2. ed. Rio de Janeiro: Embrapa-CNPS, 1997.

EUCLIDES, V. P. B. Novidades em forrageiras para a pecuária em regiões tropicais. In: SEMINÁRIO DE PASTURAS YSUPLEMENTACIÓNESTRATÉGICAEM GANADO BOVINO, 4., 2002, Asunción. Proceedings... Asunción: UNA, 2002. p. 1-12.

EUCLIDES, V. P. B. Valor alimentício de espécies forrageiras do gênero Panicum. In: SIMPÓSIO SOBRE MANEJO DA PASTAGEM, 12., 1995, Piracicaba. Anais... Piracicaba: Fealq, 1995. p. 245-276.

FRANÇA, A. F. S. et al. Parâmetros nutricionais do capimtanzânia sob doses crescentes de nitrogênio em diferentes idades de corte. Ciência Animal Brasileira, Goiânia, v. 8, n. 4, p. 695-703, 2007.

GERDES, L. et al. Avaliação de características de valor nutritivo das gramíneas forrageiras Marandu, Setária e Tanzânia nas estações do ano. Revista Brasileira de Zootecnia, Viçosa, v. 29, n. 4, p. 955-963, 2000.

GOMIDE, J. A. Produção de leite em regime de pasto. Revista Brasileira de Zootecnia, Viçosa, v. 22, n. 4, p. 591-613, 1993.

HALIM, R. A. et al. Water stress effects on alfafa forage quality after adjustment for maturity differences. Agronomy Journal, Madison, v. 81, n. 2, p. 189-194, 1989.

HANKS, R. J. et al. Line source sprinkler for continuous variable irrigation crop production studies. Soil Science of America Journal, Madison, v. 40, n. 3, p. 426-429, 1976.

MACHADO, A. O. et al. Avaliação da composição química e digestibilidade in vitro da matéria seca de cultivares e acessos de Panicum maximum Jacq. sob duas alturas de corte. Revista Brasileira de Zootecnia, Viçosa, v. 27, n. 5, p. 1057-1063, 1998. 
MARCELINO, K. R. A. et al. Manejo da adubação nitrogenada e de tensões hídricas sobre a produção de matéria seca e índice de área foliar de Tifton 85 cultivado no Cerrado. Revista Brasileira de Zootecnia, Viçosa, v. 32, n. 2, p. 268-275, 2003.

MISLEVY, P.; EVERETT, P. H. Subtropical grass species responses to different irrigation and harvest regimes. Agronomy Journal, Madison, v. 73, n. 4, p. 601-604, 1981.

REIS, R. A.; RODRIGUES, L. R. A. Valor nutritivo de plantas forrageiras. Jaboticabal: Universidade Estadual Paulista, 1993.

RICHARDS, L. A. Methods of measuring soil moisture tension. Soil Science of America Journal, Baltimore, v. 68, n. 1, p. 95-112, 1949.

SANTOS, M. V. F. et al. Produtividade e composição química de gramíneas tropicais na zona da mata de Pernambuco. Revista Brasileira de Zootecnia, Viçosa, v. 32, n. 4, p. 821-827, 2003.

SILVA, D. J.; QUEIROZ, A. C. Análises de alimentos: métodos químicos e biológicos. 3. ed. Viçosa: Imprensa Universitária, 2002.
SÓRIA, L. G. T. Produtividade do capim-tanzânia (Panicum maximum Jacq. cv. Tanzânia) em função da lâmina de irrigação e de adubação nitrogenada. 2002. 170 f. (Doutorado em Agronomia)-Escola Superior de Agricultura Luiz de Queiroz, Piracicaba, 2002.

TILLEY, J. M. A.; TERRY, R. A. A two-stage technique for the in vitro digestion of forage crops. Journal of the British Grassland Society, Oxford, v. 18, n. 2, p. 104-111, 1963.

VÁSQUEZ, R. Effects of irrigation and nitrogen levels on the yields of Guinea grass, Para grass, and Guinea Grasskudzu and Para grass-kudzu mixtures in Lajas Valley. The Journal of Agriculture of the University of Puerto Rico, Río Piedras, v. 49, n. 4, p. 389-412, 1965.

VITOR, C. M. T. Adubação nitrogenada e lâmina de água no crescimento do capim-elefante. $2006.77 \mathrm{f}$. Tese (Doutorado em Zootecnia)-Universidade Federal de Viçosa, Viçosa, 2006.

WILSON, J. R. Effects of water stress on in vitro dry matter digestibility and chemical composition of herbage of tropical pasture species. Australian Journal of Agricultural Research, Melbourne, v. 34, n. 4, p. 377-390, 1983. 